\title{
Methods to Evaluate and Measure Power of Pneumatic System and Their Applications
}

\author{
Yan Shi ${ }^{1,2}{ }^{-}$, Maolin $\mathrm{Cai}^{1}$, Weiqing $\mathrm{Xu}^{1^{*}}$ and Yixuan Wang ${ }^{1}$
}

\begin{abstract}
Pneumatic system has been widely used throughout industry, and it consumes more than billions kW h of electricity one year all over the world. So as to improve the efficiency of pneumatic system, its power evaluation as well as measurement methods should be proposed, and their applicability should be validated. In this paper, firstly, power evaluation and measurement methods of pneumatic system were introduced for the first time. Secondly, based on the proposed methods, power distributions in pneumatic system was analyzed. Thirdly, through the analysis on pneumatic efficiencies of typical compressors and pneumatic components, the applicability of the proposed methods were validated. It can be concluded that, first of all, the proposed methods to evaluation and measurement the power of pneumatic system were efficient. Furthermore, the pneumatic power efficiencies of pneumatic system in the air production and cleaning procedure are respectively about 35\%-75\% and $85 \%-90 \%$. Moreover, the pneumatic power efficiencies of pneumatic system in the transmission and consumption procedures are about $70 \%-85 \%$ and $10 \%-35 \%$. And the total pneumatic power efficiency of pneumatic system is about $2 \%-20 \%$, which varies largely with the system configuration. This paper provides a method to analyze and measure the power of pneumatic system, lay a foundation for the optimization and energy-saving design of pneumatic system.
\end{abstract}

Keywords: Pneumatic system, Compressed air, Energy assessment, Measurement, Power evaluation

\section{Introduction}

In pneumatic system, power is transmitted and controlled through compressed air within a circuit. Due to its advantages, such as the low price of its components, easy maintenance of the system, pneumatic system has been widely used throughout industries [1-3]. And now, pneumatic system has become a main energy consumption system all over the world $[4,5]$.

Energy consumption in Europe of pneumatic system accounts for probably $10 \%$ of total industrial power consumption [6]. The energy consumption of pneumatic system in the United States is about 9\% of the whole electricity consumption [7]. What is more, in China, pneumatic system consumes about $9 \%$ of the whole electricity consumption, up to 320 billion $\mathrm{kW} \cdot \mathrm{h}$ in 2009 [8].

\footnotetext{
*Correspondence: weiqing.xu@buaa.edu.cn

${ }^{1}$ School of Automation Science and Electrical Engineering, Beihang University, Beijing 100191, China

Full list of author information is available at the end of the article
}

However, the efficiency of pneumatic system is very limited as a result of improper use, poor management and low efficiency of pneumatic components, about $30 \%$ $[9,10]$. To increase the efficiency of pneumatic systems as well as the implied components, the methods to evaluate and measure the power of compressed air should be established.

Nowadays, the air volume or its rate of flow is applied to represent the air consumption [11]. But, the amount of power which is lost in supply lines or provided to actuators cannot be clarified, and that is considered extremely important for energy savings. Furthermore, fluid power in hydraulics can be expressed by multiplying the pressure of gauge as well as the volumetric flow rate of the fluid [12-14]. However, due to the compressibility of air, fluid power is unfeasible for compressed air [9].

Therefore, to evaluate the energy consumption as well as the loss of pneumatic system, and optimize the design of pneumatic components, it is necessary to propose methods to evaluate and measure power of pneumatic system. 
Through more than ten years' research [15], we have proposed methods to evaluate and measure the power of pneumatic system. The proposed methods have been employed to analyze the energy loss in different pneumatic system and components [16-18], and several energy-saving system and components have been developed [19-21]. What is more, dimensionless optimizations on the pneumatic system are also carried on [22, 23].

Wang has studied the optimization method of the pneumatic system in a hybrid power vehicle [24], he also tried the same optimizing method in the efficiency study of engine [25], and finally he summarized a frontier technology in the energy-saving technology. In addition, the dimensionless methods have been also applied in the researches of pneumatic system in Wang's works [26, 27], and the principle of efficiency calculating has great reference value.

Moreover, the proposed methods have been proposed to international standard organization as a new work item proposal.

In this paper, firstly, the methods to evaluate and measure the power of pneumatic system were introduced. Secondly, the test installation and method were proposed. Furthermore, an application case of the proposed evaluation and measurement methods was introduced, and power distributions in pneumatic system were illustrated.

This research can be referred in efficiency measurement, analysis and the optimization of pneumatic system and components.

\section{Definitions and Symbols}

The methods to evaluate and measure the power of pneumatic system, which can be used to analyze pneumatic system energy distribution, and guide the appliers to take the reasonable energy-saving technologies to promote the efficiency of pneumatic system as well as pneumatic components.

\subsection{Definitions}

In this paper, the terms and definitions given in $\mathrm{GB} / \mathrm{T}$ 17446 are adopted.

\section{(1) Available Pneumatic Energy $E$}

Potential of compressed air to output mechanical work at the atmospheric state because it goes through a reversible process from a given state to an atmospheric state since all the pneumatic systems and equipment are working at the atmospheric state. Energy conversion in pneumatic system, ideal for compressed air production and consumption are given in authors' previous work [6].

(2) Pneumatic Transmission Energy $E_{\mathrm{t}}$

Addresses the energy used to push the air downstream, which is the energy transmitted from the upstream to the downstream. This energy is not included in the internal energy of air.

(3) Pneumatic Expansion Energy $E_{\mathrm{e}}$

Addresses the maximum energy extracted to do mechanical work under atmospheric conditions by means of air expansion. This energy is included in the internal energy of air.

(4) Pneumatic Power $P$

Pneumatic power $P$ is defined as the flow of aerodynamic available energy that can be extracted from flowing air. The definition, character and application of cases of pneumatic power are given in authors' previous work [8].

(5) Pneumatic Transmission Power $P_{\mathrm{t}}$ and Pneumatic Expansion Power $P_{\mathrm{e}}$

Pneumatic transmission power $P_{\mathrm{t}}$ means the flow of pneumatic transmission energy which is able to be extracted from the flowing air.

Pneumatic expansion power $P_{\mathrm{e}}$ is treated as the flow of pneumatic expansion energy which is extracted from the flowing air.

\subsection{Symbols and Units}

The symbols and units used throughout this paper are shown in Table 1.

The numerals used as subscripts and the asterisk (*) used as a superscript to the symbols listed in Table 1 are as specified in Table 2 .

\section{Assessment and Calculation of Pneumatic Energy}

\subsection{Pneumatic Available Energy}

The consumed energy with a volume of air consumption and the supplied energy with a volume of air supply should be determined to be pneumatic available energy of the consumed air or the supplied air. As given in authors' previous work [9], the available aerodynamic energy consists of two parts: pneumatic transmission energy and pneumatic expansion energy. They can be calculated as follows by Eqs. (1), (2) and (3).

$$
E=E_{\mathrm{t}}+E_{\mathrm{e}}=p V\left[\ln \frac{p}{p_{\mathrm{a}}}+\frac{\kappa}{\kappa-1}\left(\frac{T-T_{\mathrm{a}}}{T_{\mathrm{a}}}-\ln \frac{T}{T_{\mathrm{a}}}\right)\right],
$$

where

$$
\begin{aligned}
& E_{\mathrm{t}}=\left(p-p_{\mathrm{a}}\right) V \\
& E_{\mathrm{e}}=p V\left[\ln \frac{p}{p_{\mathrm{a}}}+\frac{\kappa}{\kappa-1}\left(\frac{T-T_{\mathrm{a}}}{T_{\mathrm{a}}}-\ln \frac{T}{T_{\mathrm{a}}}\right)-\left(1-\frac{p_{\mathrm{a}}}{p}\right)\right] .
\end{aligned}
$$


Table 1 Symbols and units

\begin{tabular}{|c|c|c|c|}
\hline Description & Symbol & Dimension $^{(1)}$ & Practical units \\
\hline Pneumatic available energy per unit mass of air & e & $L^{2} T^{-2}$ & $\mathrm{~J} / \mathrm{kg}$ \\
\hline Pneumatic available energy & E & $\mathrm{ML}^{2} \mathrm{~T}^{-2}$ & J \\
\hline Enthalpy per unit mass of air & $h$ & $L^{2} T^{-2}$ & $\mathrm{~J} / \mathrm{kg}$ \\
\hline Pneumatic power & $P$ & $\mathrm{ML}^{-1} \mathrm{~T}^{-2}$ & W \\
\hline Air mass & $m$ & M & $\mathrm{kg}$ \\
\hline $\begin{array}{l}\text { Absolute pressure (equal to the relative pressure plus the } \\
\text { atmospheric pressure) }\end{array}$ & $p$ & $\mathrm{ML}^{-1} \mathrm{~T}^{-2}$ & $\mathrm{~Pa}^{(2)}$ \\
\hline Pressure drop & $\Delta p$ & $\mathrm{ML}^{-1} \mathrm{~T}^{-2}$ & $\mathrm{~Pa}$ \\
\hline Mass flow-rate & $q_{m}$ & $\mathrm{MT}^{-1}$ & $\mathrm{~kg} / \mathrm{s}$ \\
\hline Volume flow-rate at standard conditions & $q_{v}$ & $L^{3} T^{-1}$ & $\mathrm{~m}^{3} / \mathrm{s}$ \\
\hline Gas constant (for a perfect gas) & $R^{(3)}$ & $L^{2} T^{-2} \Theta^{-1}$ & $\mathrm{~J} /(\mathrm{kg} \cdot \mathrm{K})$ \\
\hline Entropy per unit mass of air & s & $L^{2} T^{-2} \Theta^{-1}$ & $J /(\mathrm{kg} \cdot \mathrm{K})$ \\
\hline Thermodynamic temperature & $T$ & $\Theta$ & K \\
\hline Velocity & u & $\mathrm{LT}^{-1}$ & $\mathrm{~m} / \mathrm{s}$ \\
\hline Volume & v & $L^{3}$ & $m^{3}$ \\
\hline Mechanical work & W & $\mathrm{ML}^{2} \mathrm{~T}^{-2}$ & J \\
\hline Isobaric specific heat & $c_{p}$ & $L^{2} T^{-2} \Theta^{-1}$ & $\mathrm{~J} /(\mathrm{kg} \cdot \mathrm{K})$ \\
\hline Specific heat ratio & $\kappa^{(4)}$ & Dimensionless parameter & \\
\hline Efficiency & $\eta$ & Dimensionless parameter & \\
\hline
\end{tabular}

(1) $M=$ mass; $L=$ length; $T=$ time; $\Theta=$ temperature

(2) $1 \mathrm{~Pa}=1 \mathrm{~N} / \mathrm{m}^{2}$

(3) $R=287 \mathrm{~J} /(\mathrm{kg} \cdot \mathrm{K})$

(4) $K=1.4$

\section{Table 2 Subscripts and superscripts}

\begin{tabular}{lll}
\hline Superscript & Subscript & Meaning \\
\hline & & Ideal process \\
* & The atmosphere \\
e & Pneumatic expansion energy or power \\
i & Manufacturing process of compressed air \\
o & Consumption process of compressed air \\
1 & Import; input \\
2 & Export; output \\
s & Air supply \\
t & Pneumatic transmission energy or power \\
k & Kinetic power of air \\
p & Isobaric \\
total & Total \\
cp & Air compressor \\
dy & Refrigeration dryer \\
fl & Filter \\
pi & Pipeline \\
Ik & Leak \\
cy & Cylinder \\
sc & Useful work \\
nu & Speed control \\
& Unuseful work \\
&
\end{tabular}

\subsection{Pneumatic Power}

The consumed power with a consumption of flowing air and the supplied power with a supply of flowing air can be determined to be pneumatic power of consumed air flow or supplied air flow. As given in authors' previous work [9], pneumatic power consists of pneumatic transmission power and pneumatic expansion power, and thy is able to be gotten as follows by Eqs. (4), (5) and (6).

$$
P=P_{\mathrm{t}}+P_{\mathrm{e}}=p q_{\mathrm{v}}\left[\ln \frac{p}{p_{\mathrm{a}}}+\frac{\kappa}{\kappa-1}\left(\frac{T-T_{\mathrm{a}}}{T_{\mathrm{a}}}-\ln \frac{T}{T_{\mathrm{a}}}\right)\right],
$$

where

$$
\begin{aligned}
& P_{\mathrm{t}}=\left(p-p_{\mathrm{a}}\right) q_{\mathrm{v}}, \\
& P_{\mathrm{e}}=p q_{\mathrm{v}}\left[\ln \frac{p}{p_{\mathrm{a}}}+\frac{\kappa}{\kappa-1}\left(\frac{T-T_{\mathrm{a}}}{T_{\mathrm{a}}}-\ln \frac{T}{T_{\mathrm{a}}}\right)-\left(1-\frac{p_{\mathrm{a}}}{p}\right)\right] .
\end{aligned}
$$

When air temperature and the atmosphere temperature are the same, pneumatic power can be given as:

$$
P=p q_{\mathrm{v}} \ln \frac{p}{p_{\mathrm{a}}} .
$$




\subsection{Evaluation Formula of Atmospheric Temperature} 3.3.1 Pneumatic Available Power

As given in authors' previous work [9], pneumatic available power can be obtained by:

$$
P=p_{\mathrm{a}} q_{\mathrm{va}} \ln \frac{p}{p_{\mathrm{a}}} .
$$

\subsubsection{Pneumatic Invalid Power}

The power which is lost when the air temperature is cooled down till the atmosphere temperature is defined as pneumatic invalid power [9], which can be given by:

$$
P=p q_{\mathrm{v}}\left[\ln \frac{p}{p_{\mathrm{a}}}+\frac{\kappa}{\kappa-1}\left(\frac{T-T_{\mathrm{a}}}{T_{\mathrm{a}}}-\ln \frac{T}{T_{\mathrm{a}}}\right)\right]-p_{\mathrm{a}} q_{\mathrm{va}} \ln \frac{p}{p_{\mathrm{a}}} .
$$

\subsubsection{Pneumatic Power Factor}

In this standard, the ratio of pneumatic available power and pneumatic power is defined as pneumatic power factor [9], and it is calculated as shown of the following equations:

$$
\varphi=1-\frac{T_{\mathrm{a}} \ln \frac{p}{p_{\mathrm{a}}}}{T\left[\ln \frac{p}{p_{\mathrm{a}}}+\frac{\kappa}{\kappa-1}\left(\frac{T}{T_{\mathrm{a}}}-1-\ln \frac{T}{T_{\mathrm{a}}}\right)\right]} .
$$

\subsection{Kinetic Power}

Kinetic power of flowing air is one kind of mechanical power, which belongs to available power. Kinetic power can be converted into pneumatic power, and it is calculated as shown of the following equations:

$$
P_{\mathrm{k}}=\frac{8\left(p_{\mathrm{a}} q_{\mathrm{va}}\right)^{3}}{R T\left(p \pi d^{2}\right)^{2}}
$$

where $P_{\mathrm{k}}$ is the kinetic power (W), $d$ means diameter of pipe line $(\mathrm{m})$.

\section{Test Installation}

Figures 1, 2, and 3 illustrate basic circuits that do not include all the safety devices necessary to prevent damage in case of component failure. Because of the safety of personnel and equipment, it is important that those responsible for the testing are responsible.

\subsection{Test Circuit for Pipe Line Test}

If the pneumatic power of air in pipe line is tested, a suitable test circuit which is shown in Figure 1 should be applied. And Figure 1(a) shall be used especially when flow, temperature and pressure are measured solely. When integrated instrument, which is composed of flow meter, temperature-measuring instrument and pressure gauge or transduce, is adopted, Figure 1(b) shall be used. It should be noted that Table 3 is the key to test circuit components.

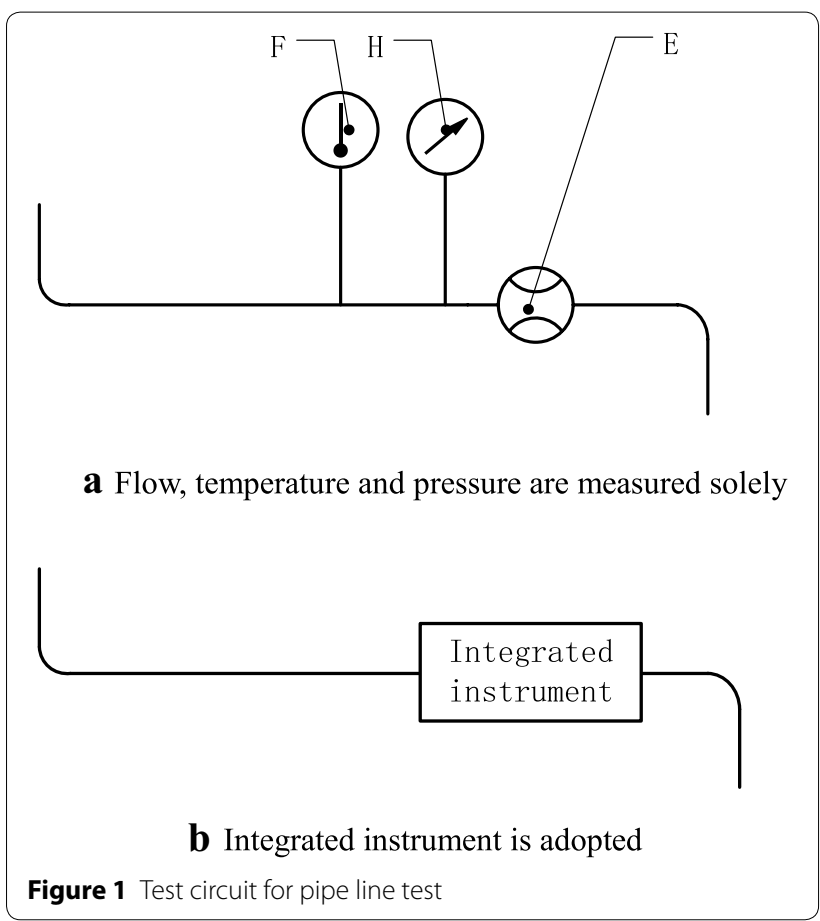

\subsection{Test Circuit for In-Line Test}

If the piezometer is connected to both upstream and downstream sides of the element under test, the corresponding test circuit shall be used as shown in Figure 2. By the way, Table 3 is the key to test circuit components.

\subsection{Test Circuit for Exhaust-to-Atmosphere Test}

If the component under test, which exhausts directly to atmosphere on its downstream side, a suitable test circuit which is shown in Figure 3 shall be applied. By the way, Table 3 is the key to test circuit components.

\subsection{General Requirements}

The components to be tested shall be installed and operated in the test circuit in accordance with the manufacturer's operating instructions. A filter should be installed which provides a standard of filtration specified by the manufacturer of the component under test.

A test circuit shall be constructed from the items listed in Table 3. Items $\mathrm{A}$ to $\mathrm{N}$ inclusive are required, and the remaining item $\mathrm{O}$ shall be chosen in accordance with Section 4.5.

All connections for pressure measurement shall be arranged in such a manner that no entrained liquid can be trapped or retained, and a drain may be provided. All connections for pressure measurement shall be arranged in such a manner that no entrained liquid can be trapped or retained, and a drain may be provided. 


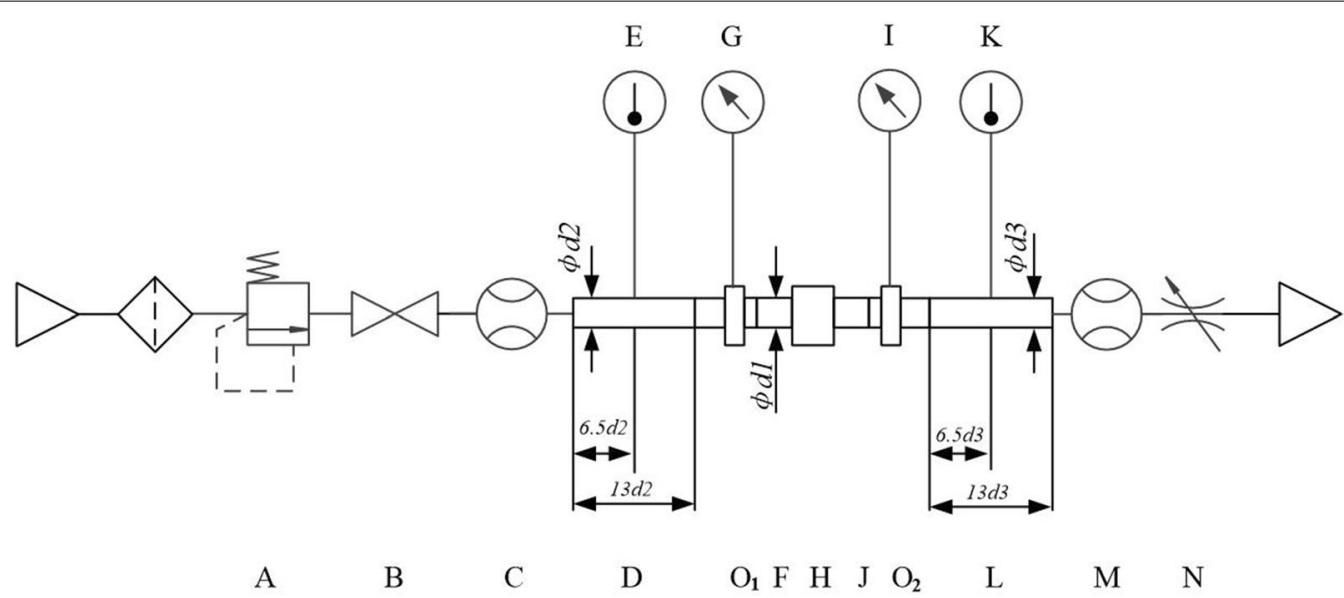

Figure 2 Circuit which is used for exhaust-to-atmosphere test

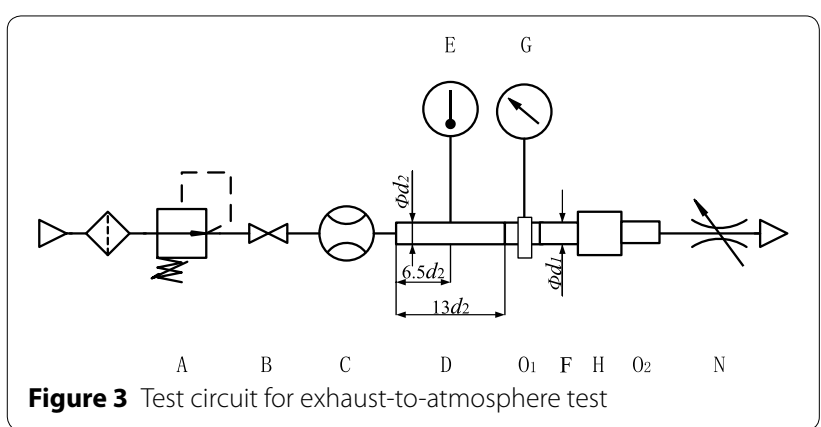

During the test, pressure drop of flow meter should be no more than $30 \mathrm{kPa}$.

When temperature of the compressed air is lower than the temperature of the atmosphere by $3{ }^{\circ} \mathrm{C}$, temperaturemeasuring instrument could not be installed.

\subsection{Other Requirements}

1. If the component under test has ports that are different from those described above in structure or size, connectors shall be used for connection with rectifier tubes.

Table 3 Keys of testing the circuit components

\begin{tabular}{|c|c|c|c|}
\hline Reference letter & Relevant subclause (s) & Description & Comments \\
\hline A & - & Adjustable pressure regulator & \\
\hline B & - & Shut-off valve & Preferably with straight flow path \\
\hline C & - & Upstream flow meter & \\
\hline $\mathrm{D}$ & 6.5 & Upstream temperature-measuring tube & \\
\hline $\mathrm{E}$ & - & Upstream temperature-measuring instrument & $\begin{array}{l}\text { Sensor located on axis of } D \text { at } \\
\text { distance }>3 d \text { upstream of the } \\
\text { end of } D\end{array}$ \\
\hline $\mathrm{F}$ & 6.5 & Transition connector upstream side & \\
\hline G & - & Upstream pressure gauge or transducer & \\
\hline $\mathrm{H}$ & - & Component under test & \\
\hline । & - & Downstream gauge meter or transducer & \\
\hline J & 6.5 & Transition connector downstream side & \\
\hline K & - & Downstream temperature-measuring instrument & \\
\hline $\mathrm{L}$ & 6.5 & Downstream temperature-measuring tube & \\
\hline M & - & Downstream flow meter & \\
\hline N & - & Flow control valve & $\begin{array}{l}\text { With a flow-rate capacity greater } \\
\text { than the component under test }\end{array}$ \\
\hline $\mathrm{O}_{1}$ & 6.5 & Upstream pressure-measuring tube & Apply to tube or thread connector \\
\hline $\mathrm{O}_{2}$ & 6.5 & Downstream pressure-measuring tube & Apply to tube or thread connector \\
\hline
\end{tabular}

Items $\mathrm{A}$ to $\mathrm{M}$ are essential and the remaining $\mathrm{N}, \mathrm{O}$ are chosen by the person conducting the test to suit the prevailing conditions 


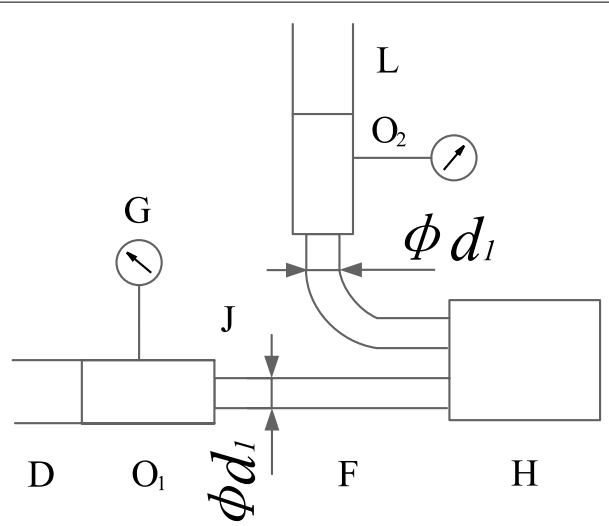

Figure 4 Connection of component under test to pressure-measuring connector using a bent tube or similar mechanism

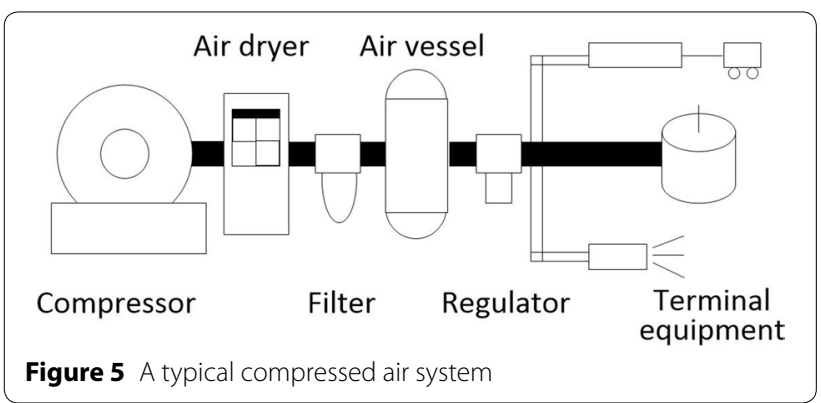

2. When the inlet and outlet ports of the component under test are different from each other in structure or size, rectifier tubes and pressure-measuring connectors that suited to the relevant ports shall be used.

3. When the pressure-measuring connector interferes with the body of component under test or an adjacent connector, a special pressure-measuring connector similar to those shown in Figures 4, 5, 6 of ISO 6358-2 shall be connected to the component under test using a bent tube or similar mechanism, as shown in Figure 4. And Table 3 is the key to test circuit components.

4. All special requirements shall be recorded in the test report.

\section{Application of the Methods: Power Distributions in Pneumatic System}

Because of the proposal of pneumatic power, it is no longer difficult to calculate efficiency of pneumatic equipment and analyze energy distribution in pneumatic system. Besides, classic pneumatic equipment and components, such as compressor, filter, dryer, pipe line, and cylinder,

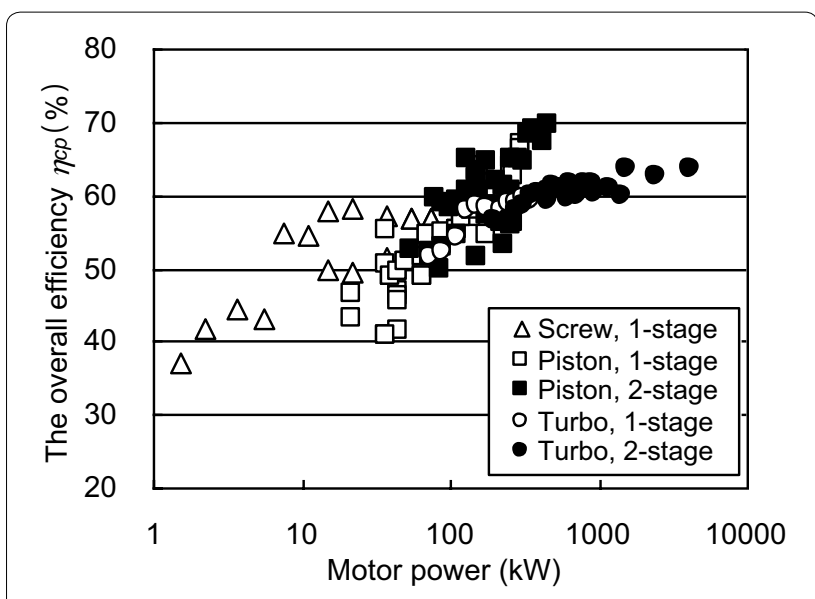

Figure 6 The overall efficiencies of compressors

etc. can be measured. This part proposes an application of power distribution in a classic pneumatic system.

The typical pneumatic system which is shown in Figure 5 is divided to 4 parts including production, clean, transport and air consume. Next, efficiencies of typical equipment in these 4 parts are discussed respectively. Meanwhile, the methods to analyze the energy losses and efficiencies of typical pneumatic equipment are introduced.

\subsection{In Air Production}

Common types of compressors are screw type, piston type, vane type and centrifugal type. Compressors are generally driven by electric motors, which are powered by electricity. The efficiency of the electric motor is generally between $80 \%$ and $96 \%$. Smaller motors $(<10 \mathrm{~kW})$ are generally less efficient.

For the power supply of compression mechanism, energy loss will be caused by mechanical friction and mixture, air leakage, insufficient cooling and other reasons. The total of these losses accounted for the lion's share of all losses. Typically, these losses account for $20 \%-40 \%$ and are different with compressor type and cooling conditions.

Comprehensive efficiency is an important index to evaluate compressor energy conversion. The overall compressor efficiency should be proposed as the following equation:

$$
\eta_{\mathrm{cp}}=\left(P_{2} / P_{1}\right) \times 100 \%,
$$

where the input energy is the total electricity which is supplied to the compressor and the intercooler, and energy output is the output of pneumatic power. The total efficiency as defined above includes the total loss of 
Table 4 Some typical compressor features

\begin{tabular}{llll}
\hline Type & $\begin{array}{l}\text { Capacity }(\mathbf{N} \cdot \mathbf{L} / \mathbf{s}) \\
(\mathbf{0 . 8} \mathbf{~ M P a})\end{array}$ & $\begin{array}{l}\text { Specific energy } \\
\left(\mathbf{k W} \cdot \mathbf{h} / \mathbf{m}^{\mathbf{3}}\right)\end{array}$ & $\boldsymbol{\eta}_{\mathbf{c p}}(\mathbf{\%})$ \\
\hline Piston & $<20$ & 0.133 & 39.6 \\
& $20-200$ & 0.095 & 55.4 \\
\multirow{2}{*}{ Vane } & $200-2000$ & 0.072 & 73.1 \\
& $<20$ & 0.125 & 42.1 \\
Screw & $20-200$ & 0.100 & 52.7 \\
& $<20$ & 0.116 & 45.4 \\
& $20-200$ & 0.100 & 52.7 \\
Centrifugal & $200-2000$ & 0.092 & 57.2 \\
& $400-1000$ & 0.091 & 57.9 \\
& $1000-2000$ & 0.083 & 63.4 \\
\hline
\end{tabular}

the compressor. User evaluation of compressor performance is a simple and practical index.

Figure 6 shows the data of some typical compressors in the market. As shown in Figure 6, the overall efficiency of compressor is within the range of $35 \%$ to $50 \%$ when the motor power is less than $10 \mathrm{~kW}, 40 \%-60 \%$ when motor power is $10-100 \mathrm{~kW}$ and $51 \%$ to $70 \%$ when the motor power is higher than $100 \mathrm{~kW}$.

In ISO 1217-Displacement Compressors Acceptance Tests, specific energy which is defined as the ratio of required motor power and air output volume, is prescribed as an energy performance index. The minimum specific energy for compressing air to $0.8 \mathrm{MPa}$ is $0.06 \mathrm{~kW} \cdot \mathrm{h} / \mathrm{m}^{3}$. In practice, however, only large piston compressors approach this number. A well-organized installation is more likely to consume 0.08 to $0.12 \mathrm{~kW} \cdot \mathrm{h} /$ $\mathrm{m}^{3}$.

In Table 4, it is the picture of actual values for some typical compressors. Considering that the motor power only accounts for $90 \%$ of the whole power consumption, then the total efficiency can be calculated. Compared with specific energy, the overall efficiency is necessary condition to evaluate the efficiency of the whole pneumatic system.

\subsection{In Air Cleaning}

The commonly used compressor types are screw, piston, vane and centrifugal type. Generally, after produced, the compressed air should be sent to the pipe network before the first air dryer and filter purification.

Refrigeration dryer is applied to cool air to the range of 0 to $10{ }^{\circ} \mathrm{C}$. According to Eq. (7), the aerodynamic power loss through the dryer can also be ignored due to the small internal pressure loss and air leakage. However, power is needed to power the refrigerator and internal cooling fans.
Table $5 K_{\mathrm{dy}}$ of some refrigeration dryer

\begin{tabular}{lllll}
\hline Type & A & B & C & D \\
\hline Applicable compressor (kW) & 2.2 & 15 & 75 & 370 \\
Assumed $\eta_{\text {cp }}(\%)$ & 40 & 50 & 50 & 60 \\
$K_{\text {dy }}$ & 0.90 & 0.96 & 0.97 & 0.97 \\
\hline
\end{tabular}

When discussing the efficiency of the entire pneumatic system, this power consumption should be added to the power consumption of the compressor. The following coefficient $K_{\mathrm{dy}}$ is recommended:

$$
\begin{aligned}
& K_{\text {dy }}=\frac{1}{\eta_{\text {cp }} \cdot\left(P_{1 \mathrm{e}} / P_{2}\right)+1}, \\
& \eta_{\text {ovr }}=\eta_{\text {ovr }} \cdot K_{\text {dy }},
\end{aligned}
$$

where $\dot{E}_{1 \mathrm{e}}$ is the dryer electricity, $\dot{E}_{2}$ is output pneumatic power, $\eta_{\text {ovr }}$ is the whole system efficiency. As is shown in Table 5, they are actual values of some refrigeration dryers in market.

In the pipe network, the commonly used air purification equipment is a filter. People invented all kinds of filters to remove different kinds of pollutants, such as water, oil, dust and so on. When the compressed air flows through the filter, the power loss is determined by the pressure loss of the filter. In general, the relationship between flow and pressure loss is given in the product catalog. According to this figure, the energy transfer efficiency of the filter is as follows:

$$
\eta_{\mathrm{fl}}=\frac{P_{2}}{P_{1}} \times 100 \%=\frac{\ln \left(\left(P_{1}-\Delta P_{\mathrm{ff}}\right) / P_{\mathrm{a}}\right)}{\ln \left(P_{1} / P_{\mathrm{a}}\right)} \times 100 \%,
$$

where $\Delta P_{\mathrm{fl}}$ refers the pressure loss. Figure 7 shows an example of a calculation. By computation efficiency of the filter in the market condition of maximum flow rate, concluded that filters the main pipe is always higher than $99 \%$, and a filter performance under $5 \mu \mathrm{m}$ terminal equipment is about $95 \%$.

\subsection{In Air Transmission}

In pipeline transmission, pressure loss and air leakage are two factors that cause aerodynamic power loss.

Pressure losses occur at piping and joints. It can be approximately calculated:

$$
\Delta P_{p p}=\frac{1}{2} K \rho \omega^{2} .
$$

However, in an actual investigation, it is hard to determine coefficient $K$ as well as the average velocity $\omega$ because in factories the pipe network is complicated and 


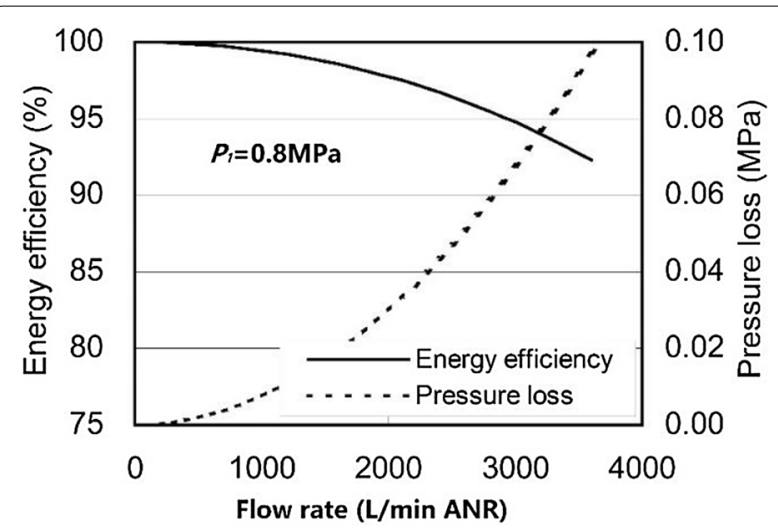

Figure 7 Picture of filter pressure loss and energy efficiency

the air flowing state is disordered. The results are compared with the theoretical results, and the measurement Suggestions are given. $\Delta P_{p p}$ is applied as the measured pressure loss, and the power loss is as follows:

$$
\Delta P_{p p}=P_{\mathrm{a}} Q_{\mathrm{a}} \ln \frac{P_{1}}{P_{1}-\Delta P_{p p}} .
$$

When air is not used, a gradual loss of pressure in the system means there is an air leak. Although the allowable amount of air leakage in industrial devices should be $5 \%$ or less, in factories, the proportion is as high as $10 \%-40 \%$.

Leaks occur frequently in pipes, hose fittings, valves, fittings, and terminal equipment. There are several ways to check for leaks. When there are no users on the system, the flow meter in the water supply pipe can be used to check the total leakage of the system. $Q_{1 \mathrm{lka}}$ is given as the flow rate of leaks, and the power being lost is:

$$
\Delta P_{\mathrm{lk}}=P_{\mathrm{a}} Q_{\mathrm{lka}} \ln \frac{P_{1}}{P_{\mathrm{a}}} .
$$

The above discussion gives the calculation method of air transmission power loss. Since these power losses vary greatly with system configuration and operating conditions, it seems impossible to display their general data.

\subsection{In Air Consumption}

It is well known that most of the compressed air is consumed by nozzles and cylinders.

The efficiency and energy distribution of the cylinder are discussed in this paper. For a cycle drive, the energy input can be made up of the following equation:

$$
E_{\mathrm{cyi}}=P_{\mathrm{a}} V_{\mathrm{a}} \ln \frac{P_{s}}{P_{\mathrm{a}}},
$$

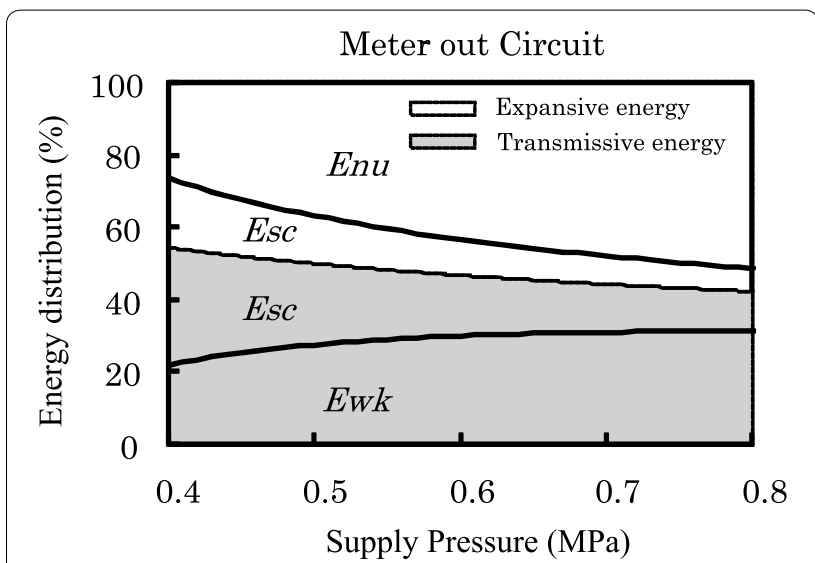

Figure 8 Energy distribution driven by an ideal meter-out cycle

where $V_{\mathrm{a}}$ is air volume consumption of one cycle actuation, and $P_{\mathrm{s}}$ is the supply pressure. $W_{\mathrm{wk}}$ is given as the mechanical work output, and the efficiency is calculated:

$$
\eta_{\mathrm{cy}}=\frac{W_{\mathrm{wk}}}{E_{\mathrm{cyi}}} \times 100 \% .
$$

In the meter-out and the meter-in circuit, the velocity controller is used to make the piston speed converge. The speed controller inevitably loses some energy because it restricts the discharge or filling of air in order to keep the air pressure in the cylinder constant. This part of energy can be considered the energy used for velocity control, and represented by $W_{\mathrm{sc}}$ in this paper.

Besides $W_{\mathrm{wk}}$ and $W_{\mathrm{sc}}$, a mount of supplied energy is exhausted to atmosphere without any application. $W_{\mathrm{nu}}$ if given as this part of energy, when there is no internal friction in the cylinder, the piston moves at a constant speed and the air state isothermal changes under the ideal drive of an external circulation of meters, the energy distribution is shown in Figure 8.

Figure 8 shows that about half of the power supply is effectively used for mechanical work and piston speed control. Since the energy consumed by non-use is expansion energy, the reuse of expansion energy is the key to energy saving of gas cylinders.

For the actual drive, the energy assigned to internal friction, piston acceleration and heat transfer is very small compared with the above three parts. Figure 8 can approximately describe the energy distribution in the actual drive.

\subsection{Power Flow in Pneumatic Systems}

Based on the above analysis, the efficiencies of the four parts can be summed up as shown in Table 6 . The total efficiency of a pneumatic system is less than $20 \%$. 
Table 6 Power flow in pneumatic cylinder actuating systems

\begin{tabular}{lll}
\hline Part & Efficiency (\%) & Detail \\
\hline Production & $35-75$ & $\leq 10 \mathrm{~kW}: 35 \%-50 \%, 10-100 \mathrm{~kW}: 40-60,>100 \mathrm{~kW}: 50 \%-70 \%$ \\
Cleaning & $85-90$ & After-cooler: $99 \%$, dryer: $90 \%-96 \%$, filter: $95 \%$ \\
Transmission & $70-85$ & Tank: above $90 \%$, pressure loss at pipe: above $97 \%$, air leaks: 10\%-20\% \\
Consumption & $10-35$ & Pneumatic cylinder: 10\%-35\%, speed control uses about 20\% of supply \\
Total & $2-20$ & Varies largely with the system configuration \\
\hline
\end{tabular}

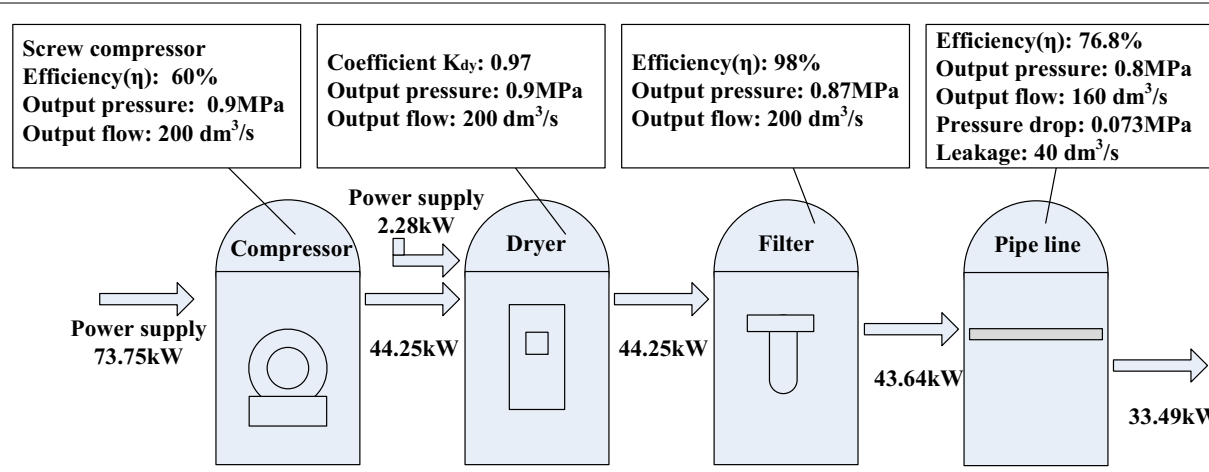

$\operatorname{Efficiency}(\eta): 25 \%$

Power of speed control(22\%): $7.37 \mathrm{~kW}$

Expansion power(53\%): $17.75 \mathrm{~kW}$

Transmission power( $(47 \%): 15.74 \mathrm{~kW}$

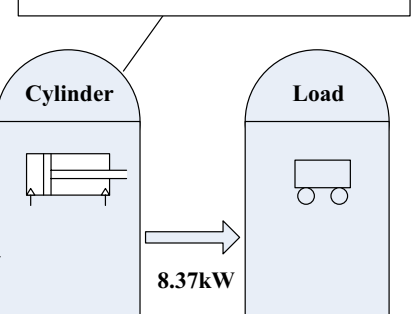

Figure 9 Energy flow in a pneumatic system

Table 7 Analysis of energy flow in a pneumatic system

\begin{tabular}{|c|c|c|c|c|c|c|}
\hline Components & $\begin{array}{l}\text { Absolute } \\
\text { pressure } \\
\text { (MPa) }\end{array}$ & $\begin{array}{l}\text { Volume } \\
\text { flow-rate } \\
\left(\mathrm{dm}^{3} / \mathrm{s}\right)\end{array}$ & $\begin{array}{l}\text { Input } \\
\text { power } \\
(\mathrm{kW})\end{array}$ & $\begin{array}{l}\text { Output } \\
\text { power } \\
(\mathrm{kW})\end{array}$ & Efficiency $^{(1)}$ & Remarks \\
\hline Compressor & Export: 0.9 & 200 & 73.75 & $44.25^{(2)}$ & $60 \%$ & Screw type, rated power: 75 kW \\
\hline Refrigeration dryer ${ }^{(3)}$ & $0.9 \rightarrow 0.9$ & $200 \rightarrow 200$ & 44.25 & 44.25 & $K_{\mathrm{dy}}=0.97$ & Power consumption: 2.28 kW \\
\hline Filter & $0.9 \rightarrow 0.873$ & $200 \rightarrow 200$ & 44.25 & 43.64 & $98 \%$ & - \\
\hline $\begin{array}{l}\text { Pipe line, connector, } \\
\text { control valve, etc. }\end{array}$ & $0.873 \rightarrow 0.8$ & $200 \rightarrow 160$ & 43.64 & 33.49 & $76.8 \%$ & $\begin{array}{l}\text { Leakage (20\%): } 40 \mathrm{dm}^{3} / \mathrm{s} \text {, pressure drop along the way } \\
\text { (8.36\%): } 0.073 \mathrm{MPa}\end{array}$ \\
\hline Cylinder & Intake: 0.8 & 160 & 33.49 & 8.37 & $25 \%$ & $\begin{array}{l}\text { Power of speed control (22\%): } 7.369 \mathrm{~kW} \text {, pneumatic } \\
\text { expansion power (53\%): } 17.75 \mathrm{~kW} \text {, pneumatic transmis- } \\
\text { sion power (47\%): } 15.742 \mathrm{~kW}\end{array}$ \\
\hline
\end{tabular}

(1) Total efficiency is equal to product of efficiencies of all components

(2) Output power of compressor here is available power

(3) Because pipe line between compressor, refrigeration dryer and filter is relatively short, pressure drop along the way and leak can be neglected, effect summation of which is considered in pipe line

Take a simple practical pneumatic system as an example, pneumatic power is used to analyze efficiency of some components and energy flow in the system, which is shown in Figure 9. Table 7 shows the related details of power flow minutely for reference.

\section{Conclusions}

In this paper, methods to evaluate and measure the power of pneumatic system were introduced. With the methods, power distributions in pneumatic system were analyzed. Through this paper, it can be concluded that:

1. The methods to evaluate and measure power of pneumatic system are proposed, which lays a founda- 
tion for development of the energy-saving pneumatic technologies and components.

2. Consider that motor power accounts for only $90 \%$ of the total power consumption, the overall pneumatic power efficiencies of piston compressor, vane compressor, screw compressor and centrifugal compressor are about $39.6 \%-73.1 \%, 42.1 \%-52.7 \%, 45.4 \%-$ $57.2 \%$ and $59.9 \%-63.4 \%$.

3. The pneumatic power efficiency of pneumatic system in the cleaning procedure is $85 \%-90 \%$ approximately, and the pneumatic power efficiencies of after-cooler, dryer and filter are about 99\%, 90\%-96\% and 95\%, respectively.

4. The pneumatic power efficiencies of pneumatic system in the transmission and consumption procedures are about $70 \%-85 \%$ respectively.

5. The total pneumatic power efficiency of pneumatic system is about $2 \%-20 \%$, which varies largely with the system configuration.

Therefore, the ways to improve the efficiency of pneumatic system are: isothermal compression of compressor, partial pressure supply of pipeline network, reduction of pressure loss and compressed air leakage, and so on.

\section{Authors' Contributions}

YS was in charge of the whole trial; YS also wrote the whole manuscript; WX assisted with sampling and laboratory analyses. All authors read and approved the final manuscript.

\section{Author Details \\ ${ }^{1}$ School of Automation Science and Electrical Engineering, Beihang University, Beijing 100191, China. ${ }^{2}$ The State Key Laboratory of Fluid Power and Mechatronic Systems, Zhejiang University, Hangzhou 310058, China.}

\section{Authors' Information}

Yan Shi is a professor at School of Automation Science and Electrical Engineering, Beihang University, China. In addition, he obtained his doctoral degree in mechanical engineering from Beihang University, China. He is major in intelligent medical devices, pneumatic control system and energy-saving of pneumatic systems.

Maolin Cai is a professor at School of Automation Science and Electrical Engineering, Beihang University, China. He got his doctor degree from Tokyo Institute of Technology, Japan. He is specialized in intelligent medical devices, technology of high efficiency and large scale compressed air energy storage.

Weiqing $\mathrm{Xu}$ is a lecturer at School of Automation Science and Electrical Engineering, Beihang University, China. He got his doctor degree in mechanical engineering from Beihang University, China. His research interests include intelligent mechanical devices and high efficient compressed air energy storage technologies.

Yixuan Wang received his B.E degree from School of Automation Science and Electrical Engineering, Beihang University, in 2015. He is currently a Ph.D. candidate at Beihang University, China. His research interests include fuel and power systems of UAV, fluid control, measurement and control system.

\section{Competing Interests}

The authors declare that they have no competing interests.

\section{Funding}

Supported by National Natural Science Foundation of China (Grants Nos. 51675020,51375028 ) and Open Foundation of the State Key Laboratory of Fluid Power and Mechatronic Systems.
Received: 2 July 2017 Accepted: 17 April 2019

Published online: 08 May 2019

\section{References}

[1] SW Mei, J J Wang, F Tian, et al. Design and engineering implementation of non-supplementary fired compressed air energy storage system: TICC500. Science China Technological Sciences, 2015, 58(4): 600-611.

[2] M Saadat, F A Shirazi, PY Li. Modeling and control of an open accumulator Compressed Air Energy Storage (CAES) system for wind turbines. Applied Energy, 2015, 137: 603-616.

[3] Sun X Q, L Chen, S H Wang, et al. Vehicle height control of electronic air suspension system based on mixed logical dynamical modelling. Science China Technological Sciences, 2015, 58(11): 1894-1904.

[4] Y Shi, M Cai. Dimensionless study on output flow characteristics of expansion energy used pneumatic pressure booster. Journal of Dynamic Systems, Measurement and Control, 2013, 135(2): 021007.

[5] D Wolf, M Budt. LTA-CAES-A low-temperature approach to adiabatic compressed air energy storage. Applied Energy, 2014, 125: 158-164.

[6] P Radgen. Efficiency through compressed air energy audits. Energy Audit Conference, 2006

[7] A P Senniappan. Baselining a compressed air system - an expert systems approach. Morgantown: West Virginia University, USA, 2004.

[8] H B Qin, A McKane. Improving energy efficiency of compressed air system based on system audit. Shanghai: Lawrence Berkeley National Laboratory, 2008

[9] M L Cai, K Kawashima, T Kagawa. Power assessment of flowing compressed air. Journal of Fluids Engineering, 2006, 128(2): 402-405.

[10] Dutch National Team, "Compressed Air: Savings of 30\% Are Quite Normal", CADDET Energy Efficiency, Newsletter, 1999(3): 14-16.

[11] S Chen, C Youn, T Kagawa, et al. Transmission and consumption of air power in pneumatic system. Energy and Power Engineering, 2014, 6(13): 487.

[12] C J Cargo, A J Hillis, A R Plummer. Strategies for active tuning of wave energy converter hydraulic power take-off mechanisms. Renewable Energy, 2016, 94: 32-47.

[13] G Yang, J Jiang. Power characteristics of a variable hydraulic transformer. Chinese Journal of Aeronautics, 2015, 28(3): 914-931.

[14] Y Lin, J Bao, H Liu, et al. Review of hydraulic transmission technologies for wave power generation. Renewable and Sustainable Energy Reviews, 2015, 50: 194-203.

[15] M L Cai, T Kagawa. Energy consumption assessment of pneumatic actuating systems including compressor. Proceedings of International Conference on Compressors and Their Systems, 2001: 381-390.

[16] Y Shi, M L Cai. Working characteristics of two kinds of air-driven boosters. Energy Conversion and Management, 2011, 52(12): 3399-3407.

[17] Y Shi, T C Wu, M L Cai, et al. Energy conversion characteristics of a hydropneumatic transformer in a sustainable-energy vehicle. Applied Energy, 2016, 171: 77-85

[18] Y Shi, T C Wu, M L Cai, et al. Modelling and study on the output flow characteristics of expansion energy used hydropneumatic transformer. Journal of Mechanical Science and Technology, 2016, 30(3): 1163-1170.

[19] P P Liao, M L Cai, Y Shi, et al. Compressed air leak detection based on time delay estimation using a portable multi-sensor ultrasonic detector. Measurement Science and Technology, 2013, 24(5): 055102.

[20] Q Xu, M L Cai, Y Shi. Dynamic heat transfer model for temperature drop analysis and heat exchange system design of the air-powered engine system. Energy, 2014, 68: 877-885.

[21] Q Y Xu, Y Shi, Q H Yu, et al. Virtual prototype modeling and performance analysis of the air-powered engine. Proceedings of the Institution of Mechanical Engineers, Part C: Journal of Mechanical Engineering Science, 2014, 228(14): 2642-2651.

[22] Q H Yu, M L Cai, Y Shi, et al. Dimensionless study on efficiency and speed characteristics of a compressed air engine. Journal of Energy Resources Technology, 2014, 137(4): 2181-2193.

[23] Y Shi, X M Tong, M L Cai. Temperature effect compensation for fast differential pressure decay testing. Measurement Science \& Technology, 2014, 25(6): 11260-11276 
[24] Y Shi, Y X Wang, M L Cai, et al. Power characteristics of a new kind of air-powered vehicle. International Journal of Energy Research, 2016, 40(8): $1112-1121$.

[25] Y X Wang, Y Shi, M L Cai, et al. Efficiency optimized fuel supply strategy of aircraft engine based on air-fuel ratio control. Chinese Journal of Aeronautics, 2019, 32(2): 489-498
[26] D K Shen, Q L Chen, Y X Wang. Dimensionless energy conversion characteristics of an air-powered hydraulic vehicle. Applied Sciences, 2018, 8(3): 347.

[27] M L Cai, Y X Wang, Y Shi, et al. Output dynamic control of a late mode sustainable energy automobile system with nonlinearity. Advances in Mechanical Engineering, 2016, 8(11): 1687814016672784.

\section{Submit your manuscript to a SpringerOpen ${ }^{\circ}$ journal and benefit from:}

- Convenient online submission

- Rigorous peer review

- Open access: articles freely available online

- High visibility within the field

- Retaining the copyright to your article

Submit your next manuscript at $\boldsymbol{\sim}$ springeropen.com 